\title{
A Simple Technique for the Generation of Dilute Mixtures of Pollutant Gases
}

\author{
W. Tsang \\ Institute for Materials Research, National Bureau of Standards, Washington, D.C. 20234
}

(November 30, 1973)

\begin{abstract}
The pyrolysis of compounds whose decomposition produces equal numbers of reactive and stable molecules provides a simple quantitative means of generating dilute mixtures of formaldehyde, acetaldehyde and acrolein. The requirements with respect to the thermal stability of such "parent" compounds are discussed and the possible extentions to other reactive gas systems are considered.
\end{abstract}

Key words: Acetaldehyde; acrolein; air pollution; calibration; decomposition; formaldehyde; reactive gases.

\section{Introduction}

The capability of generating accurately known dilute mixtures of reactive gases is important for the quantitative understanding of air pollution chemistry. For example, such mixtures are needed in the calibration of measuring instruments, in toxicity investigations and in physico-chemical studies on the rates and mechanisms of pollutant formation. The reactive nature of some of these gases may make it advisable to use dynamic methods for sample generation. This is exemplified by the use of permeation tubes for $\mathrm{SO}_{2}$ generation. A general survey on this subject can be found in a recent text [1]. ${ }^{1}$ The present report deals with the production of dilute mixtures of formaldehyde, acetaldehyde and acrolein using the gas phase pyrolysis of selected "parent" molecules. Although these aldehydes are present in automobile exhausts [2] and may be important intermediates in photochemical smog formation [3], the main aim of this investigation is to demonstrate the feasibility of this technique and to call attention to certain attractive features which make it worthy of further exploitation.

In the past formaldehyde [4], ketene [1], butadiene [1] have been generated in this manner. The prime goal has been preparative, in the sense of obtaining gases in as pure a state as possible. This study may be considered an extention to smaller concentrations of the earlier work, and as before the current application uses gas phase unimolecular reactions. Specific interest will be focused on processes of the type

$$
\mathrm{S}-\mathrm{R} \stackrel{k}{\rightarrow} \mathrm{S}+\mathrm{R}
$$

\footnotetext{
${ }^{1}$ Figures in brackets indicate the literature references at the end of this paper.
}

where $R$ is the reactive species and $S$ a stable compound for which calibration mixtures can be prepared in the ordinary manner. The concentration of $\mathrm{S}$ and $\mathrm{R}$ at any time is then

$\mathrm{S}=\mathrm{R}=(\mathrm{SR})_{\text {initial }} \times\left(1-e^{-k t}\right)$ where $k=A \exp (-E / R T)$

with $A$ and $E$ (activation energy) constants. Thus the absolute concentration of the two products is dependent on the concentration of the "parent" SR, the reaction time $t$ and the temperature $T$. However, the stoichiometry requires equal concentrations of $S$ and $R$, therefore a determination of the concentration of $\mathrm{S}$ determines the concentration of $R$. Note that this will be true regardless of the value of the three operational variables that control the absolute concentration. In other words, gas generation based on this method does not require much experimental skill in preparing the sample or in setting the reaction conditions. Furthermore, changes in concentration can be effected with ease. Here, one has the option of varying the concentration of the parent and/or the reaction temperature. For the latter a wide range of concentrations can be generated by the adjustment of a rheostat. The method also provides a convenient means of storing reactive or possibly toxic gases until needed. For example, acrolein is a very strong lachrymator and may be a hazard if carelessly handled. Finally for the calibration of a whole series of compounds $\mathbf{R}_{1}, \mathbf{R}_{2}$, etc. having parents $A R_{1}, A_{2}$, etc. it will be possible to base all the calibrations on the one set of standard samples for stable constituent A.

The aim of this study is to demonstrate that there exist compounds which behave in the desired fashion over a sufficiently wide range of reaction conditions. For this purpose it is possible to draw on the large volume of recent experimental data on molecular 
decompositions and equally important, the work of Benson and co-workers [5] in rationalizing these results. The processes of interest are those that are truly molecular in character, that is the reaction occurs as written, and which do not have significant side reactions. The avoidance of surface or chain induced decomposition processes is of prime importance. These processes are frequencly irreproducible and thus completely unsuitable for the present purposes. The monograph by Benson and O'Neal [5] suggests a large number of compounds that have the potentialities of fulfilling the requirements. They are characterized by six-centered transition states with A-factors in the $10^{12} / \mathrm{s}$ range and activation energies of between 40-50 kcal $/ \mathrm{mol}^{2}$ The latter is about $30 \mathrm{kcal} / \mathrm{mol}$ lower than that for most $\mathrm{C}-\mathrm{C}$ bond breaking reactions and provides a degree of assurance that radicals will not be present in the system. The specific reactions which are the subject of this investigation are:

(a) for formaldehyde, $\mathrm{H}_{2} \mathrm{C}=\mathrm{C}\left(\mathrm{CH}_{3}\right) \mathrm{CH}_{2} \mathrm{CH}_{2} \mathrm{OH}$ (3methyl-3-butene-1-ol) $\rightarrow i$ - $\mathrm{C}_{4} \mathrm{H}_{8}+\mathrm{HCHO}$

(b) for acetaldehyde, $\mathrm{H}_{2} \mathrm{C}=\mathrm{CHCH}_{2} \mathrm{CHOHCH}_{3}$ (3pentene-2-ol) $\rightarrow \mathrm{C}_{3} \mathrm{H}_{6}+\mathrm{CH}_{3} \mathrm{CHO}$

(c) for acrolein, (oxacyclohexene-2)

$$
\rightarrow \mathrm{C}_{2} \mathrm{H}_{4}+\mathrm{C}_{2} \mathrm{H}_{3} \mathrm{CHO}
$$

It should be emphasized that the "parent" compounds have been selected purely on the basis of availability, relative purity and other such non-critical reasons. They should not be regarded as the optimum for any particular application.

\section{Experimental Procedure}

The experimental set-up is shown schematically in figure 1. Although gas chromatographic detection is used, any other system with the necessary sensitivity is equally satisfactory. The key component is the reactor assembly and can be visualized as simply a plug-in module between the inlet and the detection system. The pyrolyzer is from Chemical Data System [6] and consists of a heated gold coil $\frac{11}{8}$ diameter and with an internal volume of about $6 \mathrm{~cm}^{3}$. With the gas chromatographic flow rates of $20-50 \mathrm{~cm}^{3} / \mathrm{min}$ heating times are of the order of seconds. The range of temperatures is from 40 to $700{ }^{\circ} \mathrm{C}$. The use of a flow reactor is necessary because of the need for delivering the desired gas mixture to the detector as rapidly as possible. Gold is employed as the reactor material since it does not appear to catalyze surface reactions. The precolumn in the reactor assembly serves to purify the input sample. The packing for the gas chromatographic columns are the various Poropaks. Column lengths are $2-6 \mathrm{ft}$., and the temperature is between 100 to $150{ }^{\circ} \mathrm{C}$. The gas chromatograph is a standard commercial instrument with flame ionization and helium ionization detectors. The last is necessary for formaldehyde detection. Peak areas are determined using an electronic integrator.

For pollution of applications, it is necessary to deliver to the detector submicrogram quantities of reactive species. Thus the use of previously diluted samples of the "parent" compound is essential. Alternatively, it would be necessary to work with microvolume samples or to carry out reactions at impractically low conversions. For introduction as a liquid sample the most convenient approach is to dissolve the "parent" compound in toluene. The concentration level is 0.2 percent or less on a mole basis. Standard gas chromatographic syringes and techniques can be used.

\footnotetext{
${ }^{2} 1 \mathrm{kcal} / \mathrm{mol}=4.184 \mathrm{~kJ} / \mathrm{mol}$.
}

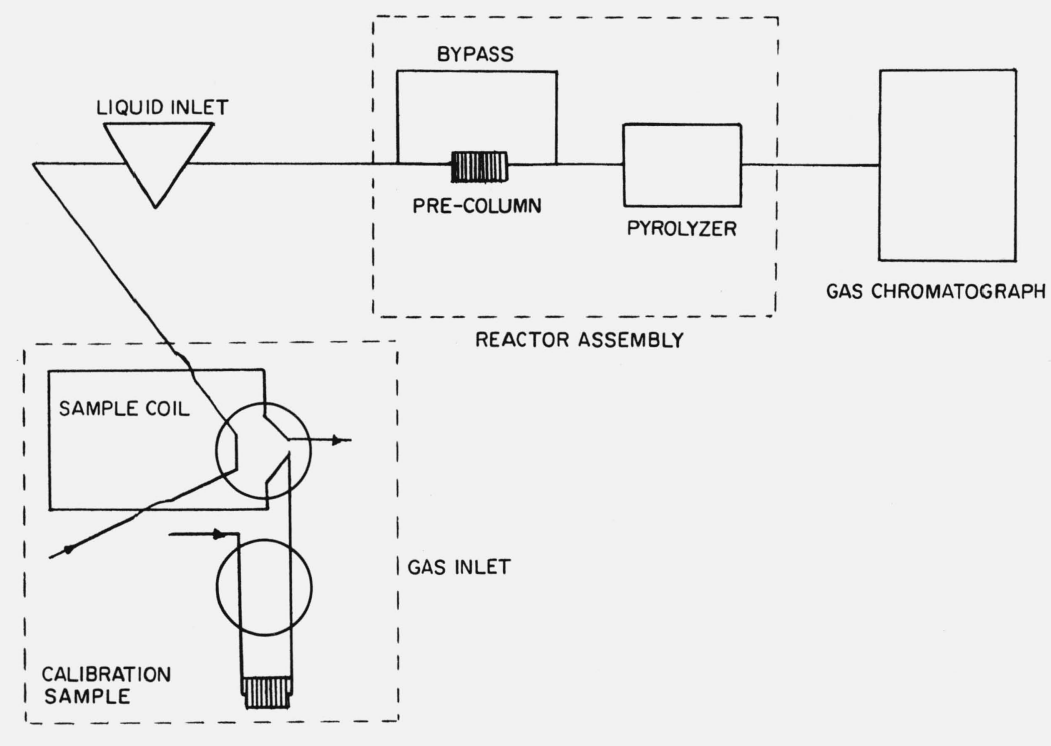

FIGURE 1. Experimental apparatus. 
Note that a $5 \mu$ l sample yields about $1 \mathrm{~cm}^{3}$ of toluene in the gas phase. The maximum possible reactive species concentration is that of the "parent" compound, while the lower limit is set by the impurities in the system and/or the detector sensitivity. An added advantage with regard to the use of toluene when the precolumn in the reactor assembly is not used is that it is an inhibitor for chain processes and thus provides an additional guarantee for the "cleanliness" of the reaction. The mixtures of alcohols in toluene appear to be stable for a period of at least six months. An adaptation of the standard bubbler technique is used for introduction as a gas. The "parent" compounds, in their pure state, are simply deposited on gas chromatographic packing (Chromosorb P, 100-200 mesh). ${ }^{3}$ When swept out by helium the fractional molar concentration is the vapor pressure of

${ }^{3}$ Certain commercial materials and equipment are identified in this paper in order to specify adequately the experimental procedure. In no case does süch identification imply recommendations or endorsement by the National Bureau of Standards. nor does it imply that the material or equipment identified is necessarily the best available for the purpose
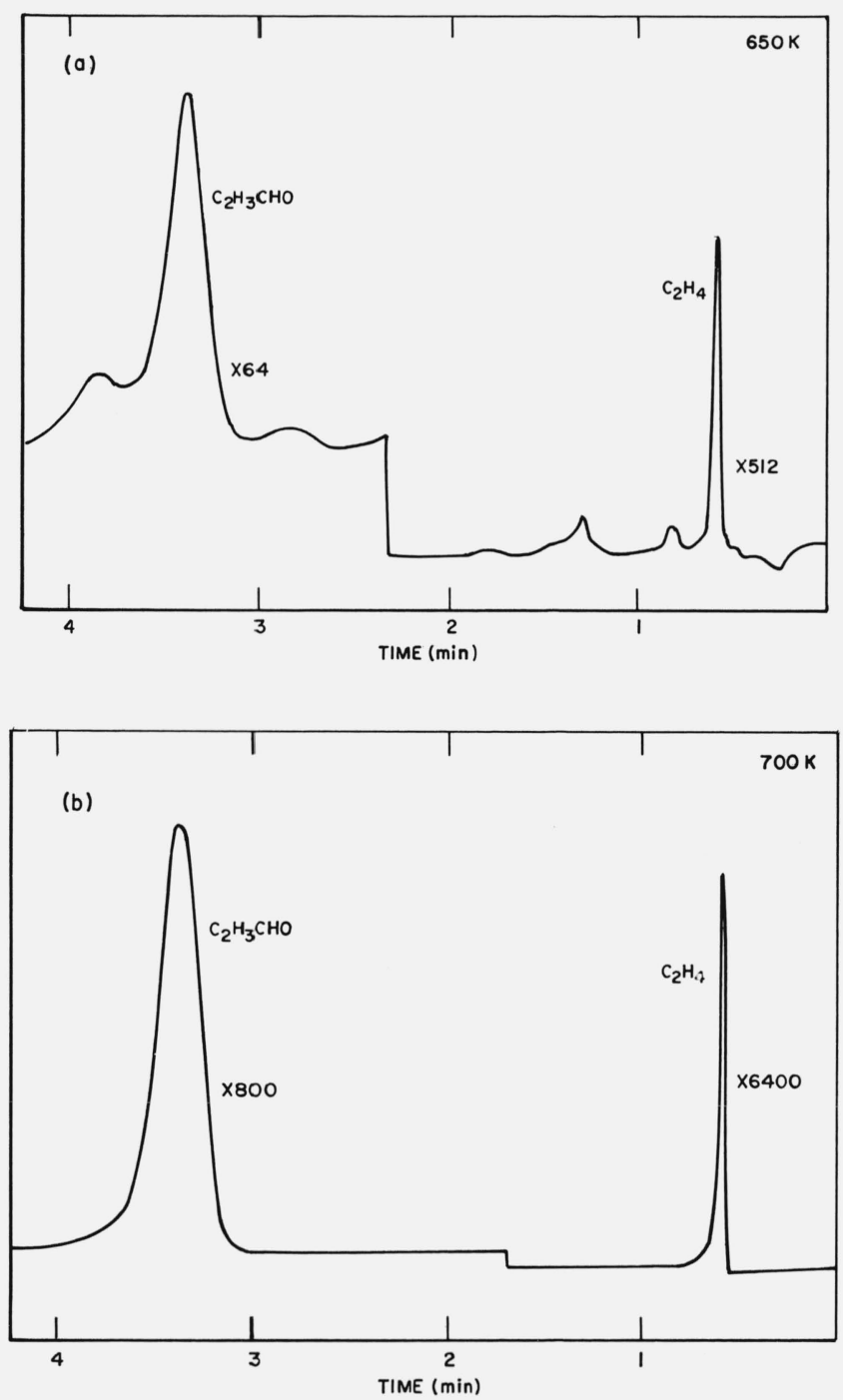

the liquid divided by the total pressure. The two alcohols are particularly suitable since their vapor pressure at $0{ }^{\circ} \mathrm{C}$ is below $1 \mathrm{~mm} \mathrm{Hg}$ and thus the mixtures produced are in the same concentration range as that from the liquid introduction. Overall, the present apparatus permits the introduction of dilute samples of various sizes in the pyrolyzer in the presence or absence of an inhibitor with or without preliminary purification. The subsequent section will demonstrate that the postulated stoichiometry is preserved under all reaction conditions.

\section{Results}

Several chromatograms from the pyrolysis experiments on oxacyclohexene- 2 are shown in figure 2. They are the results of experiments with $5 \mu \mathrm{l}$ samples of $1 / 500$ (parts by volume) oxacyclohexene- 2 in toluene (without precolumn) and are typical for this and the other two systems. The important factors are:
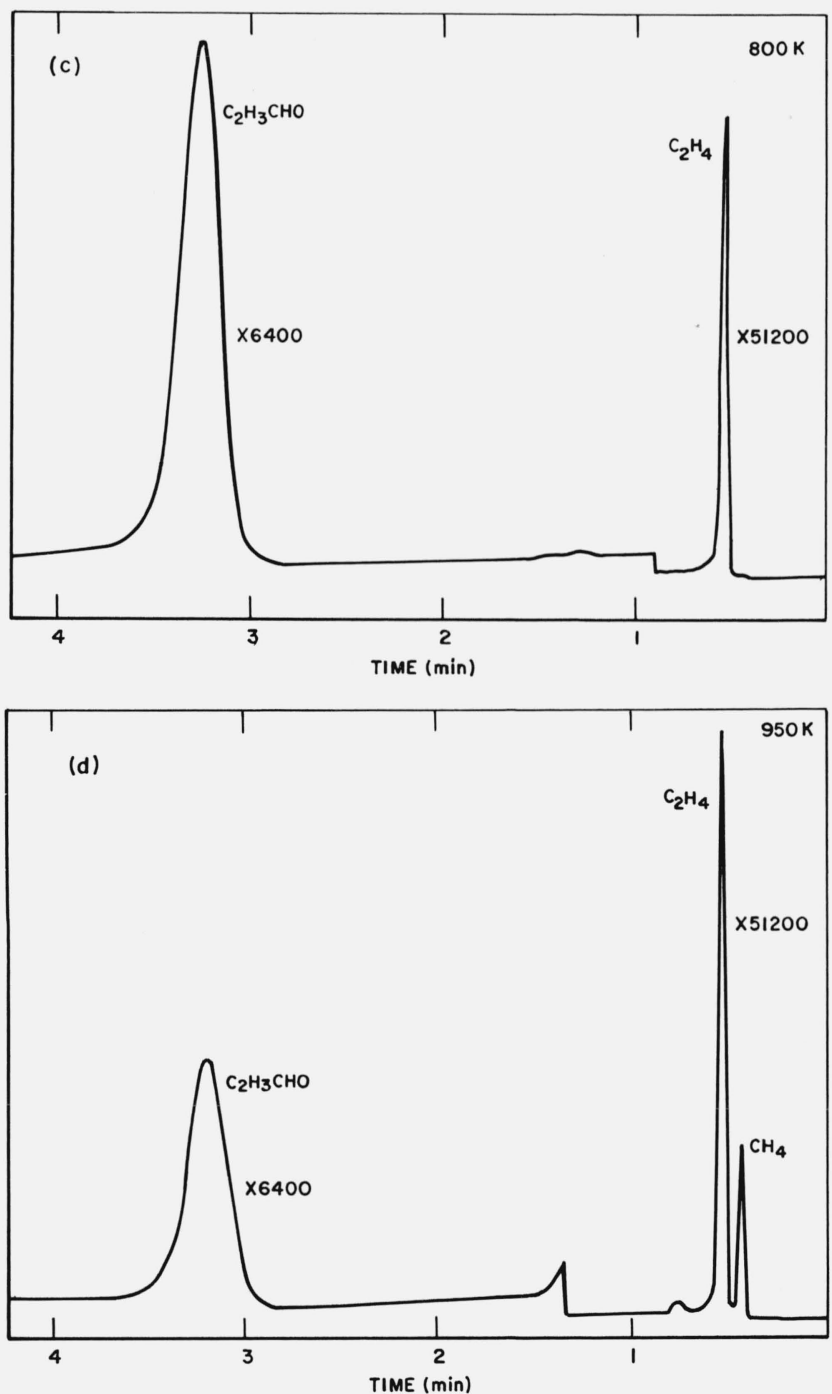

FIGURE 2. Typical chromatograms $\sim 5 \mu l$ of $1 / 500$ oxacyclohexene-2 in toluene at various temperatures. 
(a) The concentration of reactive specie extends over two orders of magnitude.

(b) In the mid-range for this case 700 to $900 \mathrm{~K}$, the chromatograms are essentially identical to each other. Note that since similar sized samples are used and the two components are created at the same time the ratio of peak heights should be a good measure of the relative concentrations and it can be seen that this is the case.

(c) At the lower limit of conversion and temperature

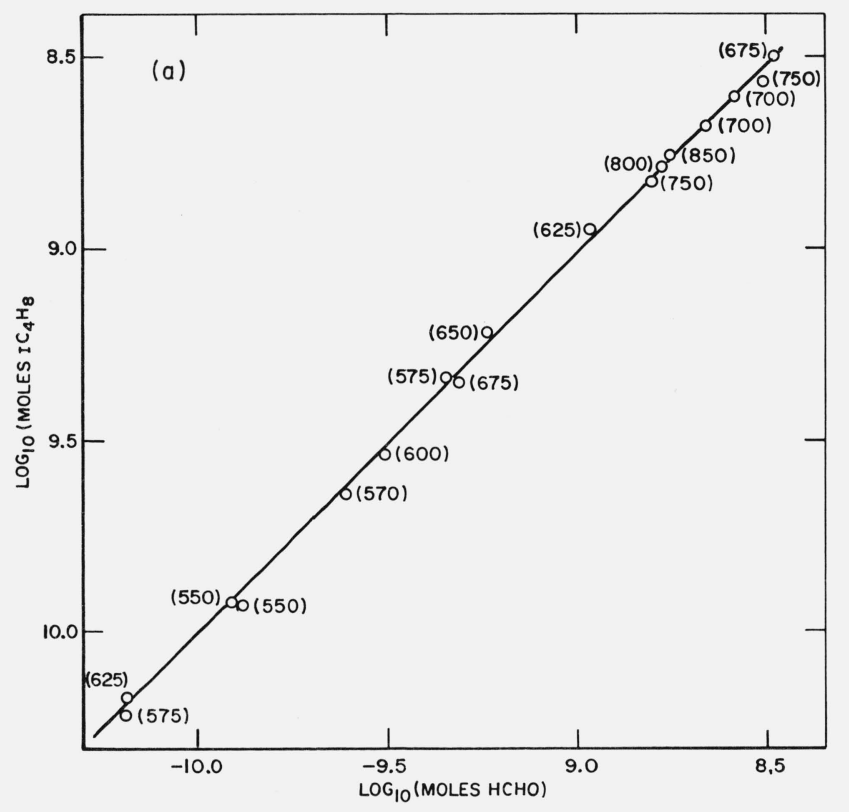

the baseline is very noisy. With the present mode of operation this is unavoidable since the extraneous peaks represent trace impurities in the oxacyclohexene-2 and/or toluene. Presumably rigorous purification will bring about some improvement. The alternative possibility of using a precolumn did not prove worth while since removal of the impurities also entails the dilution of the oxacyclohexene as it moved down the precolumn thus degrading the detectability. The simplest way of going to lower quantity of substance deliv-

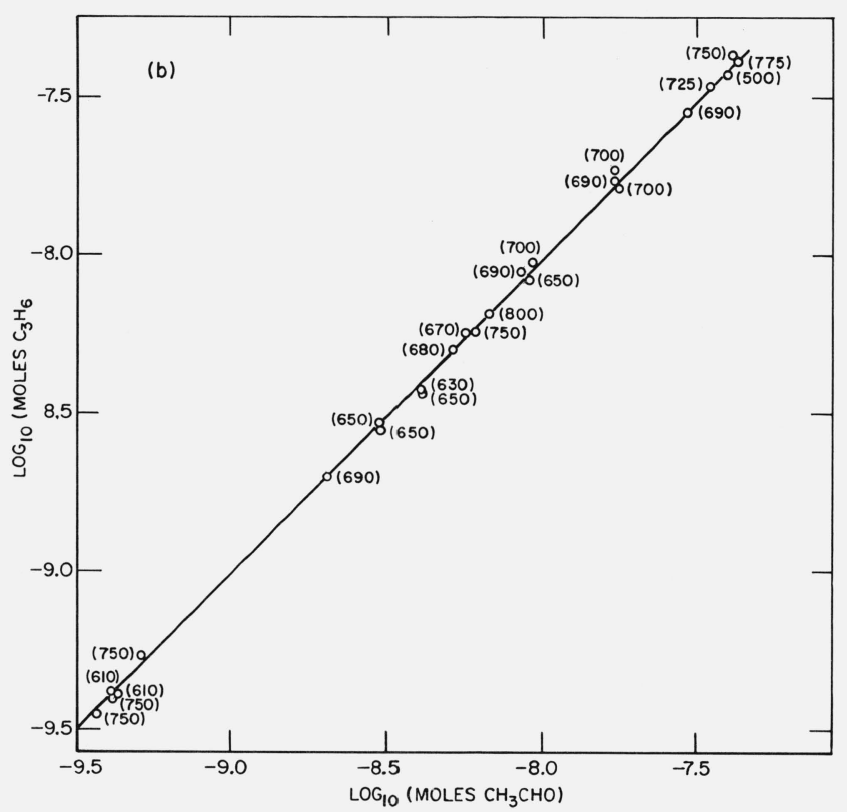

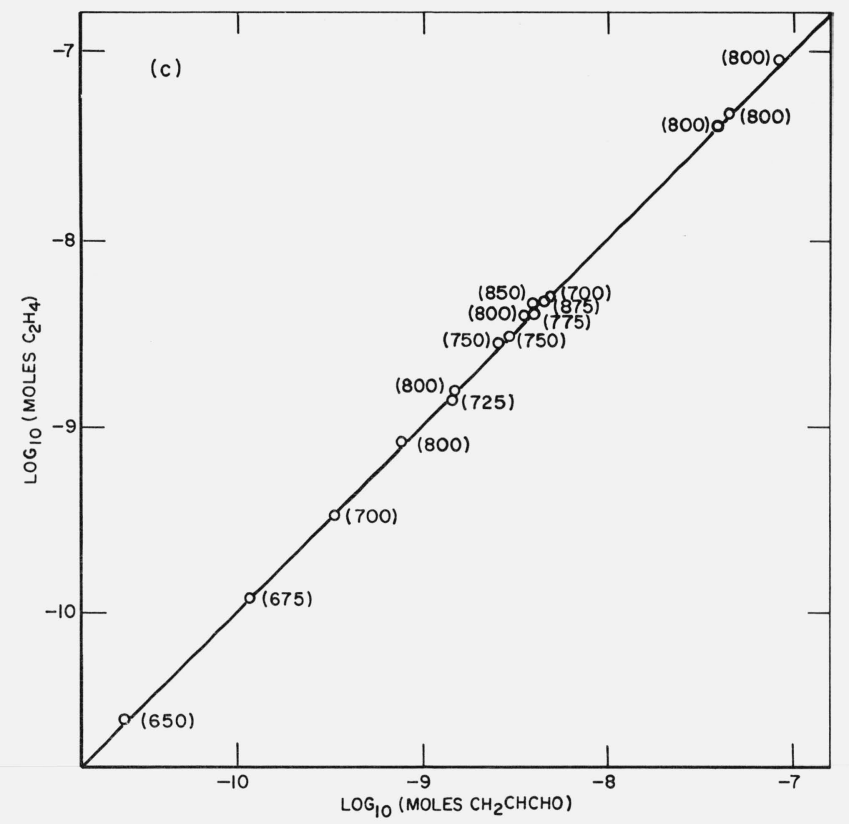

FIGURE 3. Number of moles of olefin and aldehyde delivered to the director at a given pyrolyzer temperature.

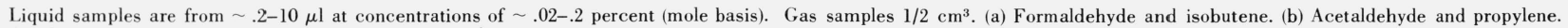
(c) Acrolein and ethylene. Line represents 1-1 correspondence 
ered to the detector is to use smaller samples at higher temperatures. Thus with a $0.5 \mu \mathrm{l}$ sample at $700 \mathrm{~K}$ a chromatogram with areas similar to that of figure $2 \mathrm{~b}$, except on the 640 and 80 scale, can be obtained.

(d) At the highest temperatures an extraneous methane peak is present. Also, the peak height ratio has now changed considerably. It is quite clear that the conditions are now such that the unimolecular decomposition process is no longer the only process occurring. The presence of methane and the noisy baseline at the low conversions serve as a warning signal that the calibration procedure may be questionable. It should be noted that in dealing with hydrocarbons under the present conditions, formation of methane is a usual product in chain decomposition processes. The same phenomenon has been observed in the two alcohol systems.

In figure 3 the results are placed on a more quantitative basis by plotting the logarithms of the total number of moles of aldehyde produced versus the number of moles of olefins for a number of different experiments. It can be seen that within the scatter of 5-10 percent there is a one-to-one correspondence between aldehyde and olefin. Furthermore, this covers over 2 to 4 orders of magnitude in moles delivered and a temperature range of several hundred degrees. They range in extent of decomposition from less than 1 percent to complete reaction during the highest 25 to 50 degrees. It is possible to carry out reactions for another $50^{\circ}$ or so before side reactions become important. In terms of a $10 \mathrm{~cm}^{3}$ air pollution sample the numbers here represent a lowest concentration of a few ppm or less. It is also important to note that these results are independent of the means of delivery or size and concentration of samples. The calibration factors for acrolein and acetaldehyde have been determined using dilute samples of pure substances. For formaldehyde the calibration factor is derived from the pyrolysis of trioxane in toluene at a temperature of $900 \mathrm{~K}$. This is a generally used technique for formaldehyde generation. The olefins are prepared as a $45 \mathrm{ppm}$ mixture in He prepared by a commercial supplier and with a stated but unconfirmed accuracy of \pm 5 percent. Checks on these calibrations have been carried out by pyrolyzing other "parent" compounds. For example, for acetaldehyde, the reaction $\mathrm{H}_{2} \mathrm{C}=\mathrm{CHOC}_{2} \mathrm{H}_{5}$ $\rightarrow \mathrm{C}_{2} \mathrm{H}_{4}+\mathrm{CH}_{3} \mathrm{CHO}$ gives area ratios of $\mathrm{A}\left(\mathrm{C}_{2} \mathrm{H}_{4}\right)$ / $\mathrm{A}\left(\mathrm{CH}_{3} \mathrm{CHO}\right) \cong 2$ on a chromatogram. This can be compared with the ratio of $\mathrm{A}\left(\mathrm{C}_{3} \mathrm{H}_{6}\right) / \mathrm{AA}\left(\mathrm{CH}_{3} \mathrm{CHO}\right) \cong 3$ from 4-pentene-2-ol or for that matter from allyl ethyl ether decomposition $\left(\mathrm{H}_{2} \mathrm{C}=\mathrm{CHCH}_{2} \mathrm{OC}_{2} \mathrm{H}_{5} \rightarrow \mathrm{C}_{3} \mathrm{H}_{6}\right.$ $+\mathrm{CH}_{3} \mathrm{CHO}$ ). The 3 to 2 ratio is the relative sensitivity of the flame ionization detector of propylene as against ethylene and has been verified from the standard olefin mixture. With regard to acrolein the reaction $\mathrm{H}_{2} \mathrm{C}=\mathrm{CH}_{2} \mathrm{CH}_{2} \mathrm{OCH}_{2} \mathrm{CH}_{3}=\mathrm{CH}_{2} \rightarrow \mathrm{C}_{3} \mathrm{H}_{6}+\mathrm{H}_{2} \mathrm{C}$ $=$ CHCHO gives an area ratio of $\mathrm{A}\left(\mathrm{C}_{3} \mathrm{H}_{6}\right) / \mathrm{A}$ (acrolein) $=3 / 2$ and can be compared with $\mathrm{A}\left(\mathrm{C}_{2} \mathrm{H}_{4}\right) / \mathrm{A}($ acrolein $)=1$ from oxacyclohexene-2 pyrolysis. Here again one observes the required 3 to 2 propylene to ethylene ratio. The sensitivity of the aldehydes to the flame ionization detector is in accord with the observation that carbonyl groups are not detectable by this means while the rest of the molecule behaves as a hydrocarbon.

It did not prove feasible to carry out these checks for formaldehyde. The use of 3-butene-1-ol and allyl methyl ether as "parents" yields propylene and formaldehyde. Unfortunately, and unexpectedly these compounds are not separated by the Poropaks to an extent that permitted accurate area measurements.

\section{Discussion}

The scatter of these results is larger than can be accounted for by uncertainties in the area measurements. There does not appear to be any simple explanation since there are no perceptible trends. This sets a limit with respect to the precision of this type of gas generation. With respect to the dynamic range it should be emphasized that the lower limit could probably be lowered if greater efforts are made to "cleanup" the system by rigorous purification. The present data represents the results achieved with readily purchasable chemicals using standard general purpose instrumentation. The highest concentrations tested here are in the range of 2000 ppm. This is probably as high as one would want to go since it is only at the lower levels that sample integrity is a problem. Overall, the entire procedure makes the generation of reactive gases a simple matter. Thus, there is no need to control temperature, sample size or method of introduction. Indeed, there is no certainty that a gold reactor is need. This point will be tested.

Although all the present data have been obtained on the basis of the introduction of a pulse of the parent compound, it should be noted that the setup for gaseous introduction can, with minor modifications, be used to generate a constant stream of reactive gases. In so far as the pyrolytic technique is concerned no new problems are introducted. Indeed the experience from kinetic studies is that continuous pyrolysis may produce more satisfactory results that that using the pulse method. Continuous generation is necessary for toxicological and physical chemical investigations. Complications will arise from the multicomponent nature of the system. The parent compound can be eliminated by working at a temperature where reaction is complete. Another reason for working in this region is that if one carries out experiments in the kinetic region, the exponential dependence of the rate constant requires sensitive temperature control. With regard to the presence of the stable compound, it may be of no importance or one can select a parent molecule which will give a standard molecule which is easily separated from the reactive species of interest.

The success of this technique for generating the desired aldehydes implies that similar reactions can be used to generate a variety of other gases. Some of these include organic acids, alcohols, ketones, hydrogen halides, ammonia, etc. Some typical reactions 
which might be utilized are as follows:

$$
\begin{aligned}
& \mathrm{CH}_{3} \mathrm{COOC}_{2} \mathrm{H}_{5} \rightarrow \mathrm{CH}_{3} \mathrm{COOH}+\mathrm{C}_{2} \mathrm{H}_{4} \\
& \mathrm{C}_{2} \mathrm{H}_{5} \mathrm{OCOOC} \mathrm{H}_{5} \rightarrow \mathrm{C}_{2} \mathrm{H}_{5} \mathrm{OH}+\mathrm{C}_{2} \mathrm{H}_{4}+\mathrm{CO}_{2} \\
& t \mathrm{C}_{4} \mathrm{H}_{9} \mathrm{Cl} \rightarrow i \mathrm{C}_{4} \mathrm{H}_{8}+\mathrm{HCl} \\
& t \mathrm{C}_{4} \mathrm{H}_{9} \mathrm{~F} \rightarrow i \mathrm{C}_{4} \mathrm{H}_{8}+\mathrm{HF}
\end{aligned}
$$

An examination of Benson and O'Neal's monograph [5], and a consideration of the criteria given here suggests that a large number of reactive gas molecules from an endless array of parent compounds may be made in this fashion. The only obvious exceptions are probably ozone and various highly oxygenated compounds.
The author is grateful to James R. McNesby for his encouragement and to the Measures for Air Quality program at the National Bureau of Standards for support.

\section{References}

[1] Nelson, G. O., Controlled Test Atmospheres. Principles and Techniques (Ann Arbor Science Publishers, Ann Arbor, Michigan, 1971).

[2] Dimitriades, B., Ellis, C. F., and Seizinger, D. E., in Advances in Chromatography, Vol. 7 (J. C. Giddings and R. A. Keller, Ed), (Dekker, New York, 1968)

[3] Altshuller, A. P., and Buffalini, J. J., Environmental Science and Technology 5, 39 (1971).

[4] Walker, J., Formaldehyde (Reinhold Publishing Co., New York, 195 1964).

[5] Benson, S. W., and O’Neal, H. E., Kinetic Data on Gạs Phase Unimolecular Reactions, Nat. Stand. Ref. Data Ser., Nat. Bur. Stand. (U.S.), 21, 645 pages (Feb. 1970).

(Paper 78A2-810) 